\title{
The effects of knowledge management and advanced technology on innovative capability
}

\author{
Mohammad Ahmad Dweiri ${ }^{a^{*}}$ and Abdallah Saleh Shatat
}

${ }^{a}$ College of Business Department of Business Administration, Al-Zaytoonah University, Jordan ${ }^{b}$ College of Administrative Sciences Department of MIS, Applied Science University, Bahrain

\section{H R O N I C L E}

\section{Article history:}

Received: November 18, 2020

Received in revised format:

December 282020

Accepted: January 2, 2021

Available online:

January 2, 2021

Keywords:

Service industries

Service innovation

Knowledge management

Advance technology

Organizational performance

\section{A B S T R A C T}

\begin{abstract}
The purpose of this paper is to examine the effects of knowledge management and advanced technology on innovative capability in order to improve the organization performance. A survey of 200 SMEs in the service industry was conducted. Partial least squares structural equation modelling (PLS_SEM) was used to test the mediation role of the service innovation on the relationships between both knowledge management and advance technology and the organizational performance. The results showed there were links between knowledge management and organizational performance. Nevertheless, it was discovered that service innovation mediated the relationship between the knowledge management and cost and financial performance, and between advance technology and cost and financial performance. The paper shows a way forward of how to measures the organizational performance in such a way that they are led from the development of innovation capability generated through knowledge management and the advance technology in the service industry.
\end{abstract}

(C) 2021 by the authors; licensee Growing Science, Canada

\section{Introduction}

In today's changing world, innovation is the key for organizations to grow and sustain in business. Organizations must innovate to stay competitive. Through innovation organization can develop new strategies to enter new markets, to increase the market share and to gain competitive position as well as to enhance the organizational performance. Innovations have been discussed from different perspectives. The word "innovation", though, has many definitions. It also means a different thing to different persons. Types of innovation are also one of the main interests of researchers. Innovations can occur at different levels of organization; individuals, groups, departments, and organizations. According to Feeny and Rogers (2003), innovation is perceived as "an interrelated bundle of new ideas" The adoption of one idea may trigger the adoption of others. According to Thomas Edison, one of the greatest innovators in history, "innovation is more than simply coming up with a good idea; it is the process of growing that idea into practical use" (Tidd \& Bessant, 1997). Recently, Du Plessis (2007) has defined innovation as "the creation of new knowledge and ideas to facilitate new business outcomes, aimed at improving internal business processes and structures and to create market driven products and services". Innovation has become a major focal point of interest for business throughout the world and is known as a key factor of a firm's success and growth. Innovation is a complex process, not many organizations are able to achieve it. So the important thing is to become success in innovation, the organization must develop the capabilities through various sources and to become successful in innovation. Innovative capability, in contrast, is the ability to innovate. According to the resource-based view (RBV) of the firm which states that resources lead to capabilities which lead to performance. A firm should identify potential markets and trends and fully utilize their capabilities to develop innovative services, along with senior executives' awareness and acceptance of risk. According to Neely et al. (2001), "an organization's innovation capability can be described as its potential to generate innovative outputs". Similarly, Lawson and Samson (2001) define innovation capability as "the ability to continuously transform knowledge and ideas into new products, processes and systems for the benefit of the firm and its stakeholders". In an organization, innovative ability is * Corresponding author.

E-mail address: Abdallah.shatat@asu.edu.bh (A. Shatat) 
to identify the needs and issues and to produce or develop ideas or products to satisfy the needs and issues of the organization and disseminate the new knowledge to all stakeholders. Innovative capabilities facilitate sustained long-term benefits and competitive advantage. As long as the organization retains the innovative capabilities it will hold the leading market share for the product or service developed by the organization. Innovative capabilities are critical to achieve a superior innovation performance.

There has been on-going quest to know why certain companies are more successful that the crowd in terms of development of innovative capability and eventually innovations outcomes. What are the recipes behind their success? What mechanism is available to blend these resources into becoming distinctive sustainable capability? Is it contextual and industry specific?

Although the scholarly literature has analyzed the innovation and innovative capabilities, there is a growing need for simultaneous analysis of the relationship between innovation sources and innovative capabilities and ultimately of the relationships between these two variables and the firm's performance. The current research is attempted to analyze the innovative capabilities within the services sectors. Few researches have been done on innovative capabilities particular to the service sector and there is a lack in the understanding of innovation sources of innovative capabilities. This paper seeks to address this gap by analyzing innovative sources and capabilities and their effect organization performance. Despite the numerous research studies have discussed about innovation capabilities and firm performance, there have been related studies done recently such as the ones by (Haldma et al., 2012); (Camisón and Villar-López, 2014); (Lin and Wu, 2014) who discussed the innovation capabilities and firm performance. However, Haldma et al. (2012) focus their study on how the linkage between innovation capability and performance measurement can be formed. The paper describes the concept of innovation capability and presents a performance measurement framework for the measurement of innovation capability and its effects. As a result, a conceptual framework with five perspectives for measuring the relationship between innovation capability and business performance is presented. Also, the link between innovation capability and an organization's business performance is disclosed. Another study by Camisón and Villar-López (2014), assesses the relationship between organizational innovation and technological innovation capabilities, and analyses their effect on firm performance using a resource-based view theoretical framework. The article presents empirical evidence from a survey of 144 Spanish firms and modelling of a system of structural equations using partial least squares. The results confirm that organizational innovation favors the development of technological innovation capabilities and that both organizational innovation and technological capabilities for products and processes can lead to superior firm performance used in the context of current literature review, Resource-based view (RBV) of innovation. Meanwhile, Lin and $\mathrm{Wu}$ (2014), conducted their study, investigated the role of dynamic capabilities in the resource-based view framework, and also explores the relationships among different resources, different dynamic capabilities and firm performance. Employing samples of top 1000 Taiwanese companies, the findings show that dynamic capabilities can mediate the firm's valuable, rare, inimitable and non-substitutable (VRIN) resources to improve performance. On the contrary, non-VRIN resources have an insignificant mediating effect. Among three types of dynamic capabilities, dynamic learning capability most effectively mediates the influence of VRIN resources on performance. Furthermore, the important role of VRIN resources is addressed because of their direct effects on performance based on RBV, as well as their indirect effect via the mediation of dynamic capabilities. The distinction of the current study is to focus on developing a framework which consists of the major source of innovation such as knowledge management and advance technology and examining their impacts on service innovation in order to enhance the organizational performance.

\section{Theoretical background and hypotheses development}

\subsection{Resource-based view (RBV) of innovation}

The theoretical framework provided by the resource based view (RBV) facilitates clear analysis of innovation and its association with performance (Damanpour et al., 2009, Galende \& de la Fuente, 2003, Mol \& Birkinshaw, 2009, Yang et al., 2009). $\mathrm{RBV}$ uses the internal features of firms to explain their heterogeneity in strategy and performance. According to the main theory of RBV, only firms with certain resources and capabilities with special characteristics will gain competitive advantages and, therefore, achieve superior firm performance. Organizations can foster innovation, only if they have the ability to constantly upgrade their products and resources and to use the full potential of their capabilities. The fundamental principles of the RBV are that resources must be valuable, uncommon, movable, imperfectly imitable and non-substitutable. Barney (1991) defines "firm resources as assets, capabilities, organizational processes, firm attributes, information, knowledge, etc., that are controlled by a firm that enable the firm to conceive of and implement strategies to improve efficiency and effectiveness. By possessing resources that are valuable (V), rare (R), inimitable (I) and which the firm is organized (O) to exploit (or the VRIO framework, cf. Barney, 2001), the firm is able to earn above-normal profits in the industry based on the inelasticity of supply. A firm's greater performance develops from its own resource-based advantages compared to its competitors. When firms possess a unique combination of resources, it can lead to the development of specific capabilities. Capabilities are also defined as "unique bundle of resources resulting from the way in which a firm assembles, integrates, and deploys the resources" (Clifford Defee and Fugate, 2010). Each organization's capabilities are different, the strength of the capability depends on the company resource, management focus and resource influence. Capabilities stand for the methods firms employ to influence performance. Creating greater capabilities can result in greater performance. RBV links resources to capabilities and capabilities to performance. Firms which successfully make use of resources to build up capabilities have the latent to produce competitive benefit follow-on in superior performance than if the resource-capability linkage was deficient. 


\subsection{Service Innovation}

Ostrom et al. (2010) define Service innovation as "creating value for customers, employees, business owners, alliance partners, and communities through new and/or improved service offerings, service processes, and service business models". A service innovation can also be a technology-based modification in the service product or in the service process (Sillanpää \& Junnonen, 2012). Service innovation shapes value creation for the customer and increases product/ market performance, efficiency, and significance. The previous research shows that there is a significantly positive relationship between customer orientation and incremental service innovation, which, in turn, leads to new service innovation. Product and/or service innovations like developing high tech products or value-added services. Firms should develop the dynamic capabilities that can facilitate service innovation. Service innovation often involves development of new procedures and concepts rather than new core technology, organizations need to be deliberative in resource allocation so the innovation effort aligns with their strategic focus on service innovation. Service innovations are intangible methods of serving users with a new level of performance. They include new service concepts, a new way to interact with customers or a new way of service delivery. As for the relationship between innovation and organizational performance, a number of studies have agreed that innovation has a positive effect on performance (Akgün et al., 2009, Carmen \& María José, 2008). The success of Apple Inc in the past several years demonstrates that innovation is central to organizational performance. The balanced scorecard (Kaplan \&Norton, 2005) also indicates that an organization's ability to innovate, improve, and learn ties directly to its performance. Innovation is economically profitable and creates competitive advantage and can have a positive impact on business performance (Fallah \& Lechler, 2008, Talke et al., 2011). "Organization performance is related to the overall firm achievements as a result of new and/or better efforts made to gain profit and growth" (Gunday et al., 2011, Hult et al., 2004). "Both financial and non-financial measures should be used to enable a firm to make efficient strategic decisions and to measure long term success"(Avci et al., 2011). "The innovation capability of a firm can impact on its business performance" (Talke et al., 2011). Zahra et al. (1999) argue that successful innovation is increasingly seen as a contributory factor to higher business performance in a number of industries and sectors, and can strengthen the competitive advantage of a firm and help a firm survive in the marketplace (Gunasekaran et al., 2000, Jiménez-Jiménez \& Sanz-Valle, 2011). Studies have shown that there is a strong relationship between determinants of innovation (such as knowledge management, human resource management, information technology, leadership, organizational learning, organizational strategy, organizational structure and organizational culture) and organizational performance (Asoh \& Belardo, 2007, Hassan \& Al-Hakim, 2011). Another study by Zack et al. (2009) found that "determinants of innovation (such as knowledge management) practices showed a direct relationship with the intermediate measures of organizational performance, and organizational performance showed a significant and direct relationship to financial performance". Calantone et al. (2002) also argued that innovation capability is closely related to organizational performance. The findings of the study of Yam et al. (2010) indicate that R\&D, resource allocation, learning, and strategy planning capabilities can significantly improve innovation sales. R\&D and resource allocation capabilities can also significantly improve new product introduction. In line with many researchers (Asoh \& Belardo, 2007, Hassan \& Al-Hakim, 2011, Akgün et al., 2009, Carmen \& María José, 2008, Kaplan \& Norton, 2005, Cohen \& Levinthal, 1990), the present study proposes that innovation plays a significant and positive mediating role in the relationship between determinants of innovation such as knowledge management and advance technology and Organizational Performance in term of cost and financial performance, based on RBV theories' perspectives that provide a theoretical basis for explaining the influence of determinants of innovation on Organizational Performance through innovation.

\subsection{Knowledge management}

Knowledge management (KM) is "a process used to create, store, retrieve, transfer, and apply knowledge" (Alavi and Leidner, 2001). As knowledge is the key quality of support organizations, creating, managing, integrating, and maintaining knowledge is considered to be significant to the endurance and accomplishment of support organizations. Guilló and García-Fernández (2013) point out that companies that have a higher degree of knowledge management through teamwork, increased empowerment, flexibility in decision-making and a general view of the company, including practices obtain better results regarding operation, but also financial and innovation results. As the ability to assimilate and use knowledge is dependent on both the receiving and diffusing units - and in particular on successful relationships between them (Lane \& Lubatkin, 1998, Schulze et al., 2014). Firms consider the acquisition of external knowledge an important element to increase their internal capabilities in order to enable them to become more innovative in the globally competitive market place (Al-Kwifi, 2012, Fontana et al., 2006). Most innovation research now explicitly acknowledge that firms need to be able to identify, assimilate and use knowledge possessed by external actors in order to enrich firm internal competencies and resources (Enkel et al., 2009, Gassmann, 2006, Hsieh \& Tidd, 2012, Huizingh, 2011). At the industry level, competition between service providers creates the urge to innovate. Therefore, for service firms, customer demand and competition are important determinants of innovation. Intensely competitive situations may push a firm to be innovative and compete through continuous development of new and improved products and services (Hurmelinna-Laukkanen \& Olander, 2014). High levels of competition increase service innovation (Lee et al., 2009). Competition enhances the organization to compete to develop the innovative capabilities and to produce innovative products / services. It creates the benefit for society from the competitive business environment. In service firms, customer demand and competition are important determinants of innovation. If the customer demand is known, then the company can initiate the innovation activities to find the service or solutions for the required customer demand. "In order to sustain service innovation initiatives over time and maintain appropriate value in the face of changing markets, technologies, and customer demands, firms must have in place processes and competencies that will allow them to transform and 
reconfigure their resource base" (Normann, 2001). Moreover, knowledge management also plays a significant role to the benefit of innovation by applying the integration of knowledge internally and externally to the organization, and make knowledge available and accessible. Thus, knowledge management tools and processes must therefore facilitate the organizational innovation. This involves linking and adaptation dynamic business information and knowledge. Without effective information and knowledge management that drives knowledge integration, which in turn underpins innovation, organizations could be underutilizing knowledge as an innovation resource (Chen et al., 2004, Cheng \& Krumwiede, 2012, Badii \& Sharif, 2003). Despite the fact that several empirical results supported the idea of "knowledge management improve organizational performance" (Schulz and Jobe, 2001, Lee et al., 2012, Wu and Chen, 2014, Mills and Smith, 2011), but other researchers argued that this assumption might simplify the nature of the link between knowledge management and organizational performance, and investing in knowledge management not may lead to improve the organizational performance (Holsapple \& Singh, 2001, Shahzad et al., 2013, Kamhawi, 2012, Bogner \& Bansal, 2007). Hence, previous literature about knowledge management did not provide a clear view and evidence about the direct effect of knowledge management on organizational performance, or if this impact was driven through intermediate factors. We expected that knowledge management has the ability to affect some of the organizational performance aspects such as organizational quality (Wilcox King and Zeithaml, 2003, Mukherjee et al., 1998), innovation output (Darroch, 2005), service innovation (Shang et al., 2009), productivity (Lapré and Van Wassenhove, 2001). Moreover, few study showed that knowledge management has a direct impact on financial performance ((Ahn and Chang, 2004, Schiuma et al., 2012); but the common approach supported that knowledge management affect the financial performance indirectly or by intermediate factors (Martín-de Castro et al., 2011, Lee \& Choi, 2003, Demarest, 1997). Thus, we can argue that knowledge management has unique contributions in the development innovation capability as well development of sustainable competitive advantage through innovation which leads to enhanced organizational performance. Therefore, this study hypothesized the following:

H1a, b: Knowledge management has an impact on the organizational performance, (a) cost and (b) financial.

H2: Knowledge management has an impact on service innovation.

H3a, b: Service innovation has an impact on the organizational performance, (a) cost and (b) financial.

$\mathrm{H} 4 \mathrm{a}$, b: Service innovation mediates the relationship between knowledge management and organizational performance, (a) cost and (b) financial.

\subsection{Advance technology}

Technology is considered as a critical component in provision of services. Higher explicitness and amassing of technology can assist the transfer of technological knowledge within the organization and can raise the capability to adopt innovative technologies. Advance technology such as ICT, ERB and SCM can help SMEs to cut cost by improving their internal processes, faster communication with customers and better distributing their products through online, increase productivity, improve inventory controls, increase sales through closer relationships and faster delivery times (Lymer, 1997), increased systems integration and higher levels of product and process innovation (Raymond \& Bergeron, 2008), providing collaborative environments (Alba et al., 2005) and improve the overall competitiveness (Bayo-Moriones and Lera-López, 2007). However, other studies show that the adoption of advanced technology in SMEs is low and because most SMEs firms do not have a sufficient budget to invest in advanced technology, advanced technologies are almost designed for large organizations, hence, SMEs need more budget to customize IT solutions to fit with their needs. There is also a hidden cost such as skill building cost and maintenance cost (Bank, 2009) Thus the adoption of advance technology and implementation becomes a real challenge for SMEs (Xie et al., 2014). As for service industry, IT is the main indicator in technology.Xue et al. (2013) identified the effect of IT on innovation. Kleis et al. (2012) linked the relationship between IT and intangible output and proposed that the use of IT in innovation and knowledge creation processes is perhaps the most critical factor in a firm's long-term success. IT improves dialogues, information and knowledge sharing and learning, which strengthen the innovation processes. Bharadwaj (2000) also demonstrated that "firms should combine IT-related resources to create unique IT capabilities, and then to create superior firm performance". During the process of technology development, firms interact and collaborate with support organizations, which permit these firms to learn, and accumulate new capabilities in order to incorporate the new technology into their processes or products (Ramachandran et al., 2012). IT use can make possible innovation when systems are synergistic and supportive. Using IT in internal communications facilitates the innovation activity of SMEs (Kmieciak et al., 2012). IT capabilities can be considered to be the mediators between IT investment and performance. Learning from imported technologies has led to higher innovation success. The use of the latest information and communication technology helps to improve organization ability to innovate. The role of information and communication technology is perceived important in relation to open innovation practices as for example help desk systems, online complaint systems, supply chain data recording systems can be good systems to get ideas and inspiration for further innovation and improvement. IT plays a main role in providing quick and easy access to external sources of knowledge and new and more intense communication channels with partner organizations, can wipe away traditional constraints on SMEs innovation ability, while leveraging their flexibility and openness. Therefore, this research hypothesized that:

H5a, b: Advance technology has an impact on the organizational performance, (a) cost and (b) financial.

H6: Advance technology has an impact on service innovation. 
H7a, b: Service innovation mediates the relationship between advance technology and organizational performance, (a) cost and (b) financial.

Fig. 1 depicts the research model, in which organizational performance is affected by knowledge management, advance technology, and service innovation. In the model, service innovation is modeled as the mediators between, knowledge management, advance technology and organizational performance.

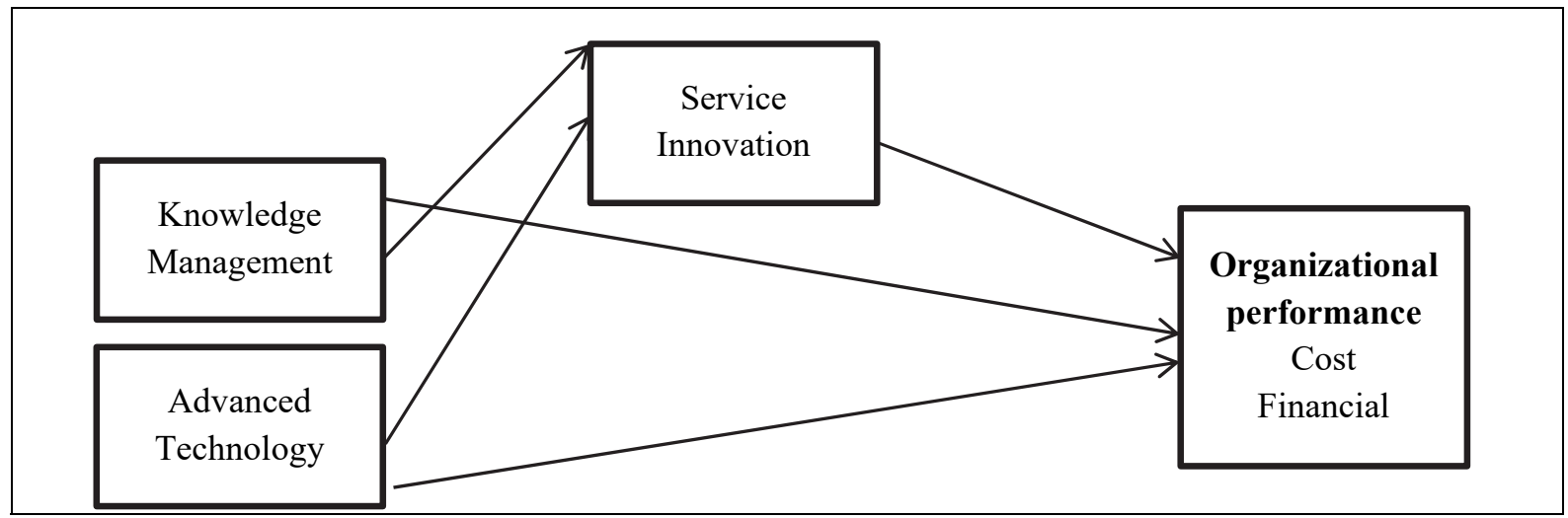

Fig. 1. Research Model

\section{Methods}

\subsection{Data}

This study focused on SMEs in Malaysian service industry. Survey techniques are used for obtaining relevant information regarding the study variables. We identified nine service industries in Malaysia and questionnaires were distributed to the firms identified in these nine industries. The questionnaires were distributed through personal visits. The researchers distributed 450 questionnaires equally amongst the firms in these nine industries and collected 209 questionnaires (46.5\% response rate). However, nine questionnaires were found to be unusable. Hence, the data analysis for this study is based on 200 questionnaires collected from firms operating within nine service industries in Malaysia.

\subsection{Measures}

Having discussed the four important blocks; knowledge management, advance technology, service innovation and performance, we used the flowing instruments to measure them:

Table 1

Company Demographic profile for the Study

\begin{tabular}{|c|c|c|c|}
\hline \multicolumn{2}{|c|}{ Demographics Variables } & \multirow{2}{*}{$\begin{array}{c}\text { Number of } \\
\text { Participants }\end{array}$} & \multirow{2}{*}{$\frac{\text { Percentage }(\%)}{4.5 \%}$} \\
\hline \multirow{9}{*}{ Type of Service } & Hotel & & \\
\hline & Fast food & 25 & $12.5 \%$ \\
\hline & Hospital & 27 & $13.5 \%$ \\
\hline & Auto repair & 27 & $13.5 \%$ \\
\hline & Retail store & 12 & $6.0 \%$ \\
\hline & Bank & 38 & $19.0 \%$ \\
\hline & Private college & 13 & $6.5 \%$ \\
\hline & Architect & 30 & $15.0 \%$ \\
\hline & Consultant & 19 & $9.5 \%$ \\
\hline \multirow{5}{*}{ Position in the Firm } & Top Manager & 6 & $3.0 \%$ \\
\hline & Senior Manager & 15 & $7.5 \%$ \\
\hline & Manager & 70 & $35.0 \%$ \\
\hline & Executives & 82 & $41.0 \%$ \\
\hline & Others & 27 & $13.5 \%$ \\
\hline \multirow{3}{*}{ Firm's Market } & Local / National & 161 & $80.5 \%$ \\
\hline & Regional & 13 & $6.5 \%$ \\
\hline & Global / International & 26 & $13.0 \%$ \\
\hline \multirow{4}{*}{ Operational Years of the Firm } & $1-3$ years & 9 & $4.5 \%$ \\
\hline & 3-6 years & 38 & $19 \%$ \\
\hline & $6-10$ years & 79 & $39 \%$ \\
\hline & more than 10 years & 74 & $37 \%$ \\
\hline
\end{tabular}

Service innovation measures, we adapted 6 items from Thakur and Hale (2013), using a seven-point Likert scale ranging from 1 strongly disagree to 7 strongly agree. For performance 7 items within 2 constructs for cost and financial performance were 
adopted and modified from many studies such as Hotel Malaysia (2009), Idris et al. (2003), Idris and Mohd Ali (2008), and Idris et al. (2010), using seven-point Likert scale ranging from 1 lower than the industry average to 7 higher than the industry average. (See appendix A). Based on the 200 samples, the profile of the organizations has been analyzed using descriptive statistics (i.e. Frequency analysis). There were $19 \%$ of the organizations within auto repair services participating in this study, and another $12 \%$ within the fast-food sector. Furthermore, $13.5 \%$ organizations are operating in the regional markets, while $80.5 \%$ in local and national markets and the rest of the organizations in global/ international markets. The operating years of the organizations are varied. Majority of the organizations 39\% have operated for $6-10$ years, while only $19 \%$ have operated for less than 3 years. This indicates the majority of the organizations targeted in this study have considerable experience in the industry. Finally, the responses show the majority of the respondents work as executive, senior managers and middle managerial positions within the organizations, which reflects their responsibility towards the knowledge management strategies, technology systems, and innovation.

\subsection{Analysis procedures}

SEM techniques are generally divided into two main approaches: covariance based SEM (Joreskog, 1970), and the variancebased SEM approach based on PLS developed by Wold (1985). Both are second generation data analysis techniques for modeling the relationships between observed indicators and latent variables, and the causal paths between latent constructs. While the use of PLS is relatively less widespread, in recent years there has been increasing interest in its use in numerous studies. We also adopted the PLS approach for several reasons. First, PLS does not require assumptions of multivariate normality for the collected data. Also, PLS has been shown to provide higher statistical power than covariance-based SEM when dealing with samples of small or moderate size (Reinartz et al., 2009). The sample size requirement for PLS corresponds to at least ten times the number of indicators for the scale with the largest number of formative (causal) indicators, or ten times the largest number of structural paths leading to an endogenous construct in the structural model (Barclay et al., 1995). In this study, the sample size of (200) was sufficiently high for PLS, since there are no formative indicators and the largest number of structural paths leading to an endogenous construct is three. Finally, PLS is considered to be particularly well-suited for explaining complex relationships (Fornell et al., 1990). We employed Smart-PLS software version 3.0 (Ringle et al., 2015) . Since PLS does not require any assumptions about the distribution of the observed variables, to assess the statistical significance of the path coefficients, which are standardized $\beta$ 's, a bootstrap resampling procedure (5000 sub-samples were randomly generated) was performed (Chin, 2010, Chin, 1998). Following Chin (2010) and Hair et al. (2013) we analyzed our model in two steps. First, we assessed the measurement model and evaluated the convergent validity, discriminant validity and reliability of the model constructs. Second, we evaluated the structural model by examining the size and significance of the path coefficients and the $\mathrm{R}^{2}$ values of the dependent variables. For the mediation effect, the researchers run the PLS algorithm on the full model to test the mediation effect. If the path coefficient for direct effect and indirect effect is statistically significant, partial mediation is expected. If the direct effect is not significant but the indirect effect is significant, full mediation is expected.

\section{Results}

\subsection{Measurement model}

The reliability and validity of the measurement model were assessed using PLS procedures. Composite reliabilities and the average variance extracted (AVE) were calculated to assess the reliability and convergent validity of our scales. The results in Table 2 show that the composite reliability and Cronbach's Alpha of all scales were above the 0.70 recommended threshold (with one $\alpha$ coefficient approaching the acceptability level). Also, the average variances extracted by our measures were all above the 0.50 acceptability level, while all factor loadings were above 0.70 threshold, providing support for convergent validity.

Table 2

The results of Cronbach's Alpha, Composite Reliability and AVE

\begin{tabular}{llll}
\hline & Cronbach's Alpha & Composite Reliability & Average Variance Extracted (AVE) \\
\hline KM & 0.955 & 0.961 & 0.714 \\
AT & 0.959 & 0.965 & 0.732 \\
SI & 0.828 & 0.884 & 0.657 \\
C & 0.701 & 0.821 & 0.613 \\
F & 0.901 & 0.930 & 0.769 \\
\hline
\end{tabular}

Table 3 shows, instead, results relevant for discriminant validity. The square root of the AVE for each construct (on the diagonal) was greater than each inter-construct correlation, which provides supports for discriminant validity.

The square root of the AVE for each construct (on the diagonal) was greater than each inter-construct correlation, which provides supports for discriminant validity. 
Table 3

The results of discriminant validity

\begin{tabular}{lccccc}
\hline & AT & C & F & KM & SI \\
\hline AT & $\mathbf{0 . 8 5 5}$ & & & & \\
C & 0.357 & $\mathbf{0 . 7 8 3}$ & $\mathbf{0 . 8 7 7}$ & & \\
F & 0.402 & 0.361 & 0.441 & $\mathbf{0 . 8 4 5}$ & \\
KM & 0.677 & 0.487 & 0.439 & 0.708 & $\mathbf{0 . 8 1 0}$ \\
SI & 0.588 & 0.440 & & \\
\hline
\end{tabular}

Notes: $n=200$. Along the diagonal: the square root of the AVEs

\subsection{Structural Model Result}

Results from our statistical analysis are reported in Table 4 and Fig. 2. To assess the statistical significance of the path coefficients a bootstrap analysis with 5000 repetitions (Chin, 1998) was performed. By following the recommendations of Zhao et al (2010), the mediating effects were tested. The $\mathrm{R}^{2}$ of the endogenous constructs were $0.523,0.238$, and 0.256 for service innovation, finance, and cost, respectively. Ston-Geisser's $Q^{2}$ for endogenous constructs were $0.319,0.65$, and 0.137 for service innovation, finance, and cost, respectively, which indicates acceptable predictive relevance.

Table 4

The results of statistical analysis

\begin{tabular}{|c|c|c|c|c|c|}
\hline & Original Sample (O) & Sample Mean (M) & $\begin{array}{c}\text { Standard Deviation } \\
\text { (STDEV) }\end{array}$ & $\begin{array}{c}\text { T Statistics } \\
(\mid \text { O/STDEV } \mid) \\
\end{array}$ & P Values \\
\hline $\mathrm{H} 1 \mathrm{a}=\mathrm{c} 1 / \mathrm{KM} \rightarrow \mathrm{C}$ & 0.345 & 0.359 & 0.127 & 2.725 & 0.006 \\
\hline $\mathbf{H} 1 \mathrm{~b}=\mathbf{c} 2 / \mathrm{KM} \rightarrow \mathbf{F}$ & 0.185 & 0.173 & 0.116 & 1.597 & 0.110 \\
\hline $\mathrm{H} 2=\mathrm{a} 1 / \mathrm{KM} \rightarrow \mathrm{SI}$ & 0.572 & 0.571 & 0.085 & 6.735 & 0.000 \\
\hline $\mathrm{H} 3 \mathbf{a}=\mathbf{b} 1 / \mathrm{SI} \rightarrow \mathrm{C}$ & 0.189 & 0.183 & 0.108 & 1.748 & 0.081 \\
\hline $\mathbf{H} 3 \mathbf{b}=\mathbf{b} 2 / \mathrm{SI} \rightarrow \mathbf{F}$ & 0.223 & 0.228 & 0.105 & 2.118 & 0.034 \\
\hline $\mathrm{H} 5 \mathrm{a}=\mathrm{c} 3 / \mathrm{AT} \rightarrow \mathrm{C}$ & 0.013 & 0.009 & 0.095 & 0.134 & 0.893 \\
\hline $\mathbf{H} 5 \mathrm{~b}=\mathrm{c} 4 / \mathrm{AT} \rightarrow \mathrm{F}$ & 0.145 & 0.156 & 0.101 & 1.445 & 0.149 \\
\hline $\mathrm{H6}=\mathrm{a} 2 / \mathrm{AT} \rightarrow \mathrm{SI}$ & 0.201 & 0.205 & 0.093 & 2.162 & 0.031 \\
\hline
\end{tabular}

Our first set of research hypotheses entails the relationship between knowledge management, innovation and organizational performance (cost and financial). The coefficient for knowledge management was found to be significant on both service innovation $(\beta=0.572, p<0.1, t=6.735)$, and cost $(\beta=0.345, p<0.1, t=2.725)$. The significant relationships support our hypotheses of positive impact of knowledge management on cost, and service innovation; thus, hypothesis H1a and hypothesis $\mathrm{H} 2$ was supported. In other hand there was no impact of knowledge management on financial performance $(\beta=0.185, p>0.1$, $t=1.597)$. Thus, hypothesis $\mathrm{H} 1 \mathrm{~b}$ was rejected. Our results suggest that service innovation has a significant and positive impact on the financial performance $(\beta=0.223, p<0.1, t=2.118)$, and cost $(\beta=0.185, p>0.1, t=1.748)$. Hence, hypothesis H3b and $\mathrm{H} 3 \mathrm{a}$ were supported. Moreover, we assumed that organizational performance was affected by the advanced technology. Our results show that advanced technology has no positive and significant effect on cost $(\beta=0.013, p>0.1, t=0.134)$, and $(\beta$ $=0.145, p>0.1, t=1.445)$. Thus, hypothesis H5a and hypothesis H5b were rejected. The relationship between advanced technology and service innovation was significant $(\beta=0.201, p<0.1, t=0.2 .162)$, hence, the hypothesis H6 was accepted. Regarding the mediation hypotheses ( H4a,b and H7a.b), we followed the approach of Zhao et al. (2010) to test the mediation relationships by bootstrapping with 5000 sub-sample as they described. For the mediation role of the service innovation between the knowledge management and cost, the direct effects (c1) was significant, and the indirect effect (a1, b1) was also significant thus hypothesis $\mathrm{H} 4 \mathrm{a}$ was accepted, and by considering the positive effect for the direct and indirect effects, service innovation plays a complementary mediation (Zhao et al., 2010). in addition, our result shows an indirect only mediation role of service innovation between the knowledge management and financial performance, while the direct relationship (c2), between the knowledge management and the financial performance was insignificant, the indirect relationship was significant $(\mathrm{a} 2, \mathrm{~b} 2)$ thus hypothesis H4b was accepted. For the mediation role of the service innovation between the advance technology and organizational performance, the results show that, service innovation plays an indirect only mediation role between the advance technology and cost, because the direct effect (c3) of advance technology on cost was not significant but the indirect effect $(\mathrm{a} 3, \mathrm{~b} 2)$ was significant thus $\mathrm{H} 7 \mathrm{a}$ was supported. Additionally, service innovation plays an indirect only mediation role between the advance technology and the financial performance, because the direct effect (c4) of advance technology on the financial performance was not significant but the indirect effect $(\mathrm{a} 4, \mathrm{~b} 4)$ was significant thus H7b was supported, (see Fig. 2, and Table 4).

\section{Discussion}

To date, little empirical work has been conducted in the area investigated by this study; most of the previous researches have focused on the antecedents of innovation within the manufacturing industry. However, it is clear that there is increasing attention to service organizations and service innovations (Ashok et al., 2016). The major objective of this study was then to investigate the relationships among the knowledge management, advance technology, service innovation and organizational performance of service organizations, and to clarify the mediating role of service innovation between the study constructs. 


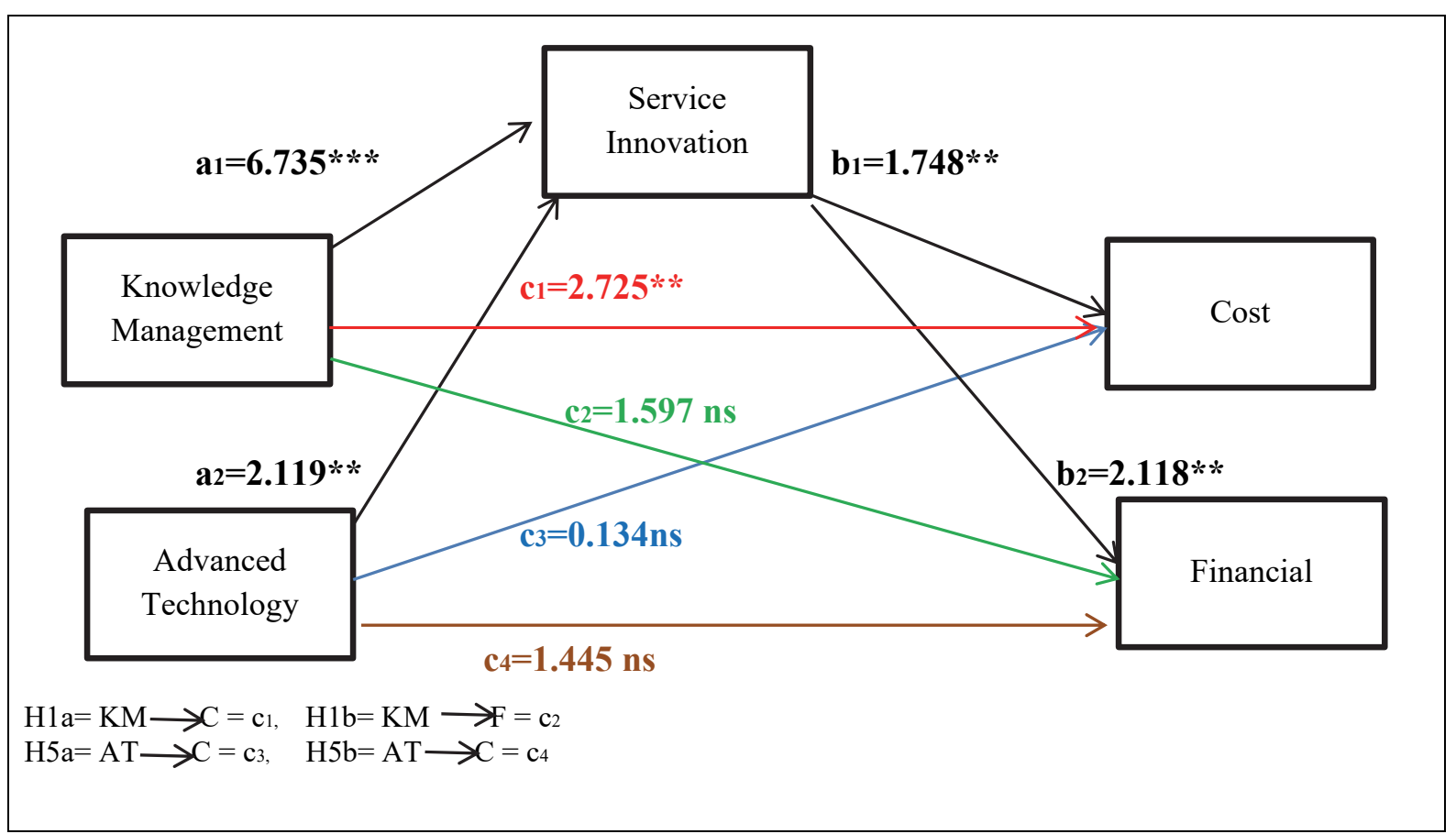

\subsection{The direct relationships}

Fig. 2. Results of the modeling analysis

In this research two organizational performance constructs were considered: cost and financial. The first finding was that knowledge management has a positive impact on the cost. The findings are in line with the idea of "knowledge management improve organizational performance" (Schulz and Jobe, 2001, Lee et al., 2012, Wu and Chen, 2014, Mills and Smith, 2011), which means that utilizing knowledge management activities within the service organizations improves the employees productivity and maintains high capacity utilization in order to reduce customer costs. However, the results showed that knowledge management has no impact on financial performance, which also supported by (Holsapple \& Singh, 2001, Shahzad et al., 2013, Kamhawi, 2012, Bogner \& Bansal, 2007), which there main arguments are that the assumption of "knowledge management improve the organizational performance" might simplify the nature of the link between knowledge management and organizational performance, and investing in knowledge management not may lead to improve the organizational performance. Moreover, we cannot ignore the fact that building a knowledge management culture within SMEs needs a huge investment, which might affect the financial situation for SMEs within the service industry. The results also showed that advanced technology has no positive impact on cost and financial performance. Regardless the benefits that SEMs within the service industry can gain such as improving their internal processes, faster communication with customers, increase productivity and increase sales through closer relationships and faster delivery times (Lymer, 1997), increased systems integration and higher levels of product and process innovation (Raymond and Bergeron, 2008), providing collaborative environments (Alba et al., 2005) and improve the overall competitiveness (Alberto \& Fernando, 2007). Adopting new technology contains a lot of cost and need a huge investment, which the SEMs do not have such as a sufficiency budget to invest in advanced technology, and advanced technologies are almost designed for large organizations, hence, SMEs need more budget to customize IT solutions to fit with their needs. There is also a hidden cost such as skill building cost and maintenance cost (Yesbank, 2009). Thus, the adoption of advanced technology and implementation becomes a real challenge for SMEs (Ying Xie 20013), thus advanced technology has no direct positive impact on the cost and financial performance. Moreover, the results suggest that service innovation has a significant and positive impact on cost and the financial performance. The findings are in line with previous researche, which claimed service innovation has an impact on the organization performance (Haldma et al., 2012, Camisón \& Villar-López, 2014, Shang et al., 2009). The results strongly suggest that knowledge management has a positive impact on service innovation, which consists of existing research, which found a positive relationship between innovation and organization performance (Chen et al., 2004, Cheng and Krumwiede, 2012, Badii and Sharif, 2003). The results also showed that adopting advanced technology also has a positive impact on service innovation and that in line with Xue et al. (2013), Kleis et al. (2012) and Kmieciak et al. (2012), they found that advanced technology improves the innovation capabilities.

\subsection{Mediation role of service innovation}

For the mediation role of the service innovation between the knowledge management and cost, the results showed a complimentary mediation role of service innovation between the knowledge management and cost. This means that knowledge management had a two ways direct impact on cost, or indirect impact through service innovation. Thus, knowledge management impact in cost would improve by service innovation. However, it is still possible to receive the knowledge management 
benefits in the absence of service innovation. The results showed that service innovation has an indirect-only mediation role between knowledge management and financial performance. This means that knowledge management has an indirect impact on financial performance through service innovation, which supports the arguments that knowledge management affects the financial performance indirectly or by intermediate factors (Martín-de Castro et al., 2011, Lee \& Choi, 2003, Demarest, 1997). Thus, the finding validated the argument that knowledge management has unique contributions in the development innovation capability as well development of sustainable competitive advantage through innovation which leads to enhance the financial performance. Regarding the mediation role of the service innovation between the advance technology and organizational performance, the results showed that service innovation plays an indirect-only mediation role between the advance technology and the financial performance, and advance technology also has an indirect-only mediation role between advance technology and cost. This means that advanced technology has no direct impact on both cost and financial performance, even so, SMEs are still able to receive the benefits of the advanced technology through service innovation. The use of latest technology helps to improve organization ability to innovate, which well develops competitive advantage leading to enhanced cost financial performance.

\subsection{Managerial implication}

The results suggested that knowledge management has a positive effect on the cost but no effect on financial performance. Therefore, the idea of utilizing the knowledge management activities will not have a concrete impact on organizational performance. Even so, the results showed that service innovation mediated the knowledge management and the organizational performance. In light of this, managers can gain the knowledge management benefits by creating an innovation culture and use the knowledge management activities in order to enhance service innovation which finally will lead to enhance the organizational performance in terms of cost and financial performance. Furthermore, the results showed that managers who would be implementing knowledge management strategies should carefully understand the innovation capabilities, in order to reach the improvements, they look for in the organization performance as the financial or operational level. The findings of this study, also showed that advanced technology have no positive direct impact on cost and financial performance. This means that SMEs are very sensitive to the cost of the new technology; hence, managers should have enough awareness of their organization's financial situation, the cost of the technology as well as they need to have the ability to make the bargaining between the cost and the benefits of adopting new technology. However, the results showed that service innovation have mediation role between advanced technology and cost and financial performance. In light of this, managers can fully utilize the advanced technology through service innovation. Thus, managers who responsible for adopting and implementing the new technologies should give a good attention for the service innovation capabilities within the organization, precisely when they choosing the technology tools to fit with their organization and the innovation and knowledge culture within the organization to maximize the benefits of the technological tools and to reach the desired improvements in the organizational performance.

\section{Summary and conclusion}

The impact of knowledge management on the cost of the service organization is evident and is both direct and mediated by service innovation. No direct effect of knowledge management on financial performance is found. However, knowledge management does appear to require services innovation to enhance the financial performance. The findings have shown that service innovation has a direct impact on cost and financial performance. Moreover, the finding showed that service innovation plays an indirect-only mediation role between advanced technology and cost and financial performance. In this study we focused and examined the cost and financial performance, leaving aside other performance dimensions, leaving these dimensions to be examined in future research. Moreover, future research can also investigate other determinants of innovation such as culture, management support and internal research and development. This research was conducted on SMEs operating within the service industry in Malaysian; by collecting data from nine different services sectors. Thus, the generalizability of the results would be limited and might not be extended to other business environments or even on other developing countries. Also, future research might focus in one sector such as hotel or consulting firms. Despite the limitations, this research has made several contributions: first, it provides empirical evidence of the mediation role of the service innovation between knowledge management and cost and financial performance and between advanced technology and cost and financial performance. Theoretically, resource-based view was used to develop the study framework in innovation research. Moreover, significant and insignificant relationships between the research variables have corroborated with the finding of other researchers' previous studies.

\section{References}

Ahn, J. H., \& Chang, S. G. (2004). Assessing the contribution of knowledge to business performance: the KP3 methodology. Decision Support Systems, 36(4), 403-416.

Akgün, A. E., Keskin, H., \& Byrne, J. (2009). Organizational emotional capability, product and process innovation, and firm performance: An empirical analysis. Journal of Engineering and Technology Management, 26(3), 103-130.

Al-Kwifi, O. S. (2012). Implementing strategic renewal by collective organisational learning. Journal for International Business and Entrepreneurship Development, 6(2), 125-141. 
Alavi, M., \& Leidner, D. E. (2001). Knowledge management and knowledge management systems: Conceptual foundations and research issues. MIS quarterly, 25, 107-136.

Alba, M., Díez, L., Olmos, E., \& Rodríguez, R. (2005, September). Global performance management for small and medium-sized enterprises (GPM-SME). In Working Conference on Virtual Enterprises (pp. 313-320). Springer, Boston, MA.

Schiuma, G., Andreeva, T., \& Kianto, A. (2012). Does knowledge management really matter? Linking knowledge management practices, competitiveness and economic performance. Journal of knowledge management, 16, 617-636.

Ashok, M., Narula, R., \& Martinez-Noya, A. (2016). How do collaboration and investments in knowledge management affect process innovation in services?. Journal of Knowledge Management, 20, 1004-1024.

Asoh, D. A., \& Belardo, S. (2007). Assessing knowledge management: Refining and cross validating the knowledge management index using structural equation modeling techniques. International Journal of Knowledge Management (IJKM), 3(2), 1-30.

Avci, U., Madanoglu, M., \& Okumus, F. (2011). Strategic orientation and performance of tourism firms: Evidence from a developing country. Tourism Management, 32(1), 147-157.

Badii, A., \& Sharif, A. (2003). Information management and knowledge integration for enterprise innovation. Logistics Information Management, 16, 145-155.

Bank, Y. (2009). Technology for financial efficiency. YES BANK's Knowledge Banking Publication.

Barclay, D., Higgins, C., \& Thompson, R. (1995). The partial least squares (PLS) approach to casual modeling: personal computer adoption ans use as an Illustration, 2, 285-309.

Barney, J. (1991). Firm resources and sustained competitive advantage. Journal of management, 17(1), 99-120.

Bayo-Moriones, A., \& Lera-López, F. (2007). A firm-level analysis of determinants of ICT adoption in Spain. Technovation, 27(67), 352-366.

Bharadwaj, A. S. (2000). A resource-based perspective on information technology capability and firm performance: an empirical investigation. MIS Quarterly, 24(1), 169-196.

Bogner, W. C., \& Bansal, P. (2007). Knowledge management as the basis of sustained high performance. Journal of Management Studies, 44(1), 165-188.

Calantone, R. J., Cavusgil, S. T., \& Zhao, Y. (2002). Learning orientation, firm innovation capability, and firm performance. Industrial Marketing Management, 31(6), 515-524.

Camisón, C., \& Villar-López, A. (2014). Organizational innovation as an enabler of technological innovation capabilities and firm performance. Journal of Business Research, 67(1), 2891-2902.

Carmen, C., \& José, G. M. (2008). The role of technological and organizational innovation in the relation between market orientation and performance in cultural organizations. European Journal of Innovation Management, 11, 413-434.

Chen, J., Zhu, Z., \& Xie, H. Y. (2004). Measuring intellectual capital: a new model and empirical study. Journal of Intellectual capital, 5, 195-212.

Cheng, C. C., \& Krumwiede, D. (2012). The role of service innovation in the market orientation-new service performance linkage. Technovation, 32(7-8), 487-497.

Chin, W. W. (1998). Commentary: Issues and opinion on structural equation modeling, MIS Quarterly, 22(1), 7-16.

Chin, W. W. (2010). How to write up and report PLS analyses. In Handbook of partial least squares (pp. 655-690). Springer, Berlin, Heidelberg.

Defee, C. C., \& Fugate, B. S. (2010). Changing perspective of capabilities in the dynamic supply chain era. The International Journal of Logistics Management, 21, 180-206.

Cohen, W. M., \& Levinthal, D. A. (1990). Absorptive capacity: A new perspective on learning and innovation. Administrative Science Quarterly, 35, 128-152.

Damanpour, F., Walker, R. M., \& Avellaneda, C. N. (2009). Combinative effects of innovation types and organizational performance: A longitudinal study of service organizations. Journal of Management studies, 46(4), 650-675.

Darroch, J. (2005). Knowledge management, innovation and firm performance. Journal of Knowledge management, 9, $101-115$.

Demarest, M. (1997). Understanding knowledge management. Long Range Planning, 30, 321374-322384.

Du Plessis, M. (2007). The role of knowledge management in innovation. Journal of Knowledge Management, 11, 20-29.

Enkel, E., Gassmann, O., \& Chesbrough, H. (2009). Open R\&D and open innovation: exploring the phenomenon. R\&d Management, 39(4), 311-316.

Fallah, M. H., \& Lechler, T. G. (2008). Global innovation performance: Strategic challenges for multinational corporations. Journal of Engineering and Technology Management, 25(1-2), 58-74.

Feeny, S., \& Rogers, M. (2003). Innovation and performance: Benchmarking Australian firms. Australian Economic Review, 36(3), 253-264.

Fontana, R., Geuna, A., \& Matt, M. (2006). Factors affecting university-industry R\&D projects: The importance of searching, screening and signalling. Research policy, 35(2), 309-323.

Fornell, C., Lorange, P., \& Roos, J. (1990). The cooperative venture formation process: A latent variable structural modeling approach. Management science, 36(10), 1246-1255.

Galende, J., \& de la Fuente, J. M. (2003). Internal factors determining a firm's innovative behaviour. Research Policy, 32(5), 715736.

Gassmann, O. (2006). Opening up the innovation process: towards an agenda. $R \& d$ Management, 36(3), 223-228.

Guilló, J. J. T., \& García-Fernández, M. (2013). Can knowledge management influence firms' performance?. Cuadernos de Gestión, 13(01), 151-176

Gunasekaran, A., Forker, L., \& Kobu, B. (2000). Improving operations performance in a small company: a case study. International Journal of Operations \& Production Management, 20, 316-336.

Gunday, G., Ulusoy, G., Kilic, K., \& Alpkan, L. (2011). Effects of innovation types on firm performance. International Journal of production economics, 133(2), 662-676. 
Hair Jr, J. F., Hult, G. T. M., Ringle, C., \& Sarstedt, M. (2016). A primer on partial least squares structural equation modeling (PLSSEM). Sage publications.

Haldma, T., Näsi, S., Grossi, G., Saunila, M., \& Ukko, J. (2012). A conceptual framework for the measurement of innovation capability and its effects. Baltic Journal of Management, 7, 355-375.

Hassan, S., \& Al-Hakim, L. A. Y. (2011). The relationships among critical success factors of knowledge management, innovation and organizational performance: A conceptual framework. 2011 International Conference on Management and Artificial Intelligence.

Holsapple, C. W., \& Singh, M. (2001). The knowledge chain model: activities for competitiveness. Expert systems with applications, 20(1), 77-98.

Hsieh, K. N., \& Tidd, J. (2012). Open versus closed new service development: The influences of project novelty. Technovation, 32(11), 600-608.

Huizingh, E. K. (2011). Open innovation: State of the art and future perspectives. Technovation, 31(1), 2-9.

Hult, G. T. M., Hurley, R. F., \& Knight, G. A. (2004). Innovativeness: Its antecedents and impact on business performance. Industrial marketing management, 33(5), 429-438.

Hurmelinna-Laukkanen, P., \& Olander, H. (2014). Coping with rivals' absorptive capacity in innovation activities. Technovation, 34(1), 3-11.

Jiménez-Jiménez, D., \& Sanz-Valle, R. (2011). Innovation, organizational learning, and performance. Journal of business research, 64(4), 408-417.

Jöreskog, K. G. (1970). A general method for analysis of covariance structures. Biometrika, 57(2), 239-251.

Kamhawi, E. M. (2012). Knowledge management fishbone: a standard framework of organizational enablers. Journal of Knowledge Management, 16, 808-828.

Kaplan, R. S., \& Norton, D. P. (2005). The balanced scorecard: measures that drive performance. Harvard business review, 83(7), 172.

Kleis, L., Chwelos, P., Ramirez, R. V., \& Cockburn, I. (2012). Information technology and intangible output: The impact of IT investment on innovation productivity. Information Systems Research, 23(1), 42-59.

Kmieciak, R., Michna, A., \& Meczynska, A. (2012). Innovativeness, empowerment and IT capability: evidence from SMEs. Industrial Management \& Data Systems, 112, 707-728.

Lane, P. J., \& Lubatkin, M. (1998). Relative absorptive capacity and interorganizational learning. Strategic management journal, 19(5), 461-477.

Lapré, M. A., \& Van Wassenhove, L. N. (2001). Creating and transferring knowledge for productivity improvement in factories. Management Science, 47(10), 1311-1325.

Lawson, B., \& Samson, D. (2001). Developing innovation capability in organisations: a dynamic capabilities approach. International journal of innovation management, 5(03), 377-400.

Lee, H., \& Choi, B. (2003). Knowledge management enablers, processes, and organizational performance: An integrative view and empirical examination. Journal of management information systems, 20(1), 179-228.

Lee, R. P., Ginn, G. O., \& Naylor, G. (2009). The impact of network and environmental factors on service innovativeness. Journal of Services Marketing, 23, 397-406.

Lee, S., Kim, B. G., \& Kim, H. (2012). An integrated view of knowledge management for performance. Journal of Knowledge management, 16, 183-203.

Lin, Y., \& Wu, L. Y. (2014). Exploring the role of dynamic capabilities in firm performance under the resource-based view framework. Journal of business research, 67(3), 407-413.

Lymer, A., Johnson, R., \& Baldwin, A. (1997, June). The Internet and the Small Business: A Study of Impacts. In ECIS (pp. 145163).

Martín-de Castro, G., López-Sáez, P., Delgado-Verde, M., Andreeva, T., \& Kianto, A. (2011). Knowledge processes, knowledgeintensity and innovation: a moderated mediation analysis. Journal of knowledge management, 15, 1016-1034.

Mills, A. M., \& Smith, T. A. (2011). Knowledge management and organizational performance: a decomposed view. Journal of knowledge management, 15, 156-171.

Mol, M. J., \& Birkinshaw, J. (2009). The sources of management innovation: When firms introduce new management practices. Journal of Business Research, 62(12), 1269-1280.

Mukherjee, A. S., Lapré, M. A., \& Van Wassenhove, L. N. (1998). Knowledge driven quality improvement. Management Science, 44(11-part-2), S35-S49.

Neely, A., Filippini, R., Forza, C., Vinelli, A., \& Hii, J. (2001). A framework for analysing business performance, firm innovation and related contextual factors: perceptions of managers and policy makers in two European regions. Integrated manufacturing systems, 12, 114-124.

Normann, R. (2001). Reframing business: When the map changes the landscape. John Wiley \& Sons.

Ostrom, A. L., Bitner, M. J., Brown, S. W., Burkhard, K. A., Goul, M., Smith-Daniels, V., ... \& Rabinovich, E. (2010). Moving forward and making a difference: research priorities for the science of service. Journal of service research, 13(1), 4-36.

Ramachandran, J., Pant, A., \& Pani, S. K. (2012). Building the BoP Producer Ecosystem: The Evolving Engagement of F abindia with I ndian Handloom Artisans. Journal of Product Innovation Management, 29(1), 33-51.

Raymond, L., \& Bergeron, F. (2008). Enabling the business strategy of SMEs through e-business capabilities. Industrial Management \& Data Systems, 108, 577-595.

Reinartz, W., Haenlein, M., \& Henseler, J. (2009). An empirical comparison of the efficacy of covariance-based and variance-based SEM. International Journal of research in Marketing, 26(4), 332-344.

Ringle, C. M., Wende, S., \& Becker, J. M. (2015). SmartPLS 3. Boenningstedt: SmartPLS GmbH. 
Schulz, M., \& Jobe, L. A. (2001). Codification and tacitness as knowledge management strategies: an empirical exploration. The Journal of High Technology Management Research, 12(1), 139-165.

Schulze, A., Brojerdi, G., \& von Krogh, G. (2014). Those who know, do. Those who understand, teach. Disseminative capability and knowledge transfer in the automotive industry. Journal of Product Innovation Management, 31(1), 79-97.

Shahzad, K., Zia, S. A., Aslam, M. H., Syed, A. R., \& Bajwa, S. U. (2013). Role of organizational vision and adaptability in knowledge management. Problems and perspectives in management, (11, Iss. 2), 24-34.

Shang, S. S., Lin, S. F., \& Wu, Y. L. (2009). Service innovation through dynamic knowledge management. Industrial Management \& Data Systems, 109, 322-337.

Sillanpää, E., \& Junnonen, J. M. (2012). Factors affecting service innovations in FM service sector. Facilities, 30, 517-530.

Talke, K., Salomo, S., \& Kock, A. (2011). Top management team diversity and strategic innovation orientation: The relationship and consequences for innovativeness and performance. Journal of Product Innovation Management, 28(6), 819-832.

Thakur, R., \& Hale, D. (2013). Service innovation: A comparative study of US and Indian service firms. Journal of Business Research, 66(8), 1108-1123.

Tidd, J., \& Bessant, J. R. (2020). Managing innovation: integrating technological, market and organizational change. Wiley.

Wilcox King, A., \& Zeithaml, C. P. (2003). Measuring organizational knowledge: a conceptual and methodological framework. Strategic Management Journal, 24(8), 763-772.

Wold, H. (1985). Encyclopedia of statistical sciences. Partial least squares. Wiley, New York, 581-591.

Wu, L., \& Chen, J. L. (2014). Knowledge management driven firm performance: the roles of business process capabilities and organizational learning. Journal of Knowledge Management, 18, 1141-1164.

Xie, Y., Allen, C. J., \& Ali, M. (2014). An integrated decision support system for ERP implementation in small and medium sized enterprises. Journal of Enterprise Information Management, 27, 358-384.

Xue, L., Ray, G., \& Sambamurthy, V. (2012). Efficiency or innovation: How do industry environments moderate the effects of firms' IT asset portfolios?. MIS quarterly, 36, 509-528.

Yam, R. C., Lo, W., Tang, E. P., \& Lau, K. W. (2010). Technological Innovation Capabilities and Firm Performance. World Academy of Science, Engineering and Technology, International Journal of Social, Behavioral, Educational, Economic, Business and Industrial Engineering, 4, 1056-1064.

Yang, C. C., Marlow, P. B., \& Lu, C. S. (2009). Assessing resources, logistics service capabilities, innovation capabilities and the performance of container shipping services in Taiwan. International Journal of Production Economics, 122(1), 4-20.

Zack, M., McKeen, J., \& Singh, S. (2009). Knowledge management and organizational performance: an exploratory analysis. Journal of knowledge management, 13, 392-409.

Zahra, S. A., Nielsen, A. P., \& Bogner, W. C. (1999). Corporate entrepreneurship, knowledge, and competence development. Entrepreneurship theory and practice, 23(3), 169-189.

Zhao, X., Lynch Jr, J. G., \& Chen, Q. (2010). Reconsidering Baron and Kenny: Myths and truths about mediation analysis. Journal of consumer research, 37(2), 197-206.

\section{Appendix (A)}

Questionnaires

\begin{tabular}{|c|c|c|c|c|c|c|c|c|}
\hline \multicolumn{9}{|c|}{ Innovation } \\
\hline \multicolumn{9}{|c|}{ Service innovation } \\
\hline \multicolumn{9}{|c|}{ Answer with score in range 1 to $7(1=$ Strongly Disagree, to $4=$ Neither Agree nor Disagree, to $7=$ Strongly } \\
\hline \multirow{2}{*}{ No } & \multirow[b]{2}{*}{$\begin{array}{l}\text { Please indicate the degree of emphasis which your } \\
\text { business on the following activities }\end{array}$} & \multicolumn{2}{|c|}{ verv low } & & & & \multicolumn{2}{|c|}{ verv High } \\
\hline & & 1 & & & & & & \\
\hline 1 & a service/product that was totally new to the company. & 1 & 2 & 3 & 4 & 5 & 6 & 7 \\
\hline 2 & $\begin{array}{l}\text { a service/product that allowed the company to enter new } \\
\text { market. }\end{array}$ & 1 & 2 & 3 & 4 & 5 & 6 & 7 \\
\hline 3 & $\begin{array}{l}\text { a service/product that created a new product line for the } \\
\text { company. }\end{array}$ & 1 & 2 & 3 & 4 & 5 & 6 & 7 \\
\hline 4 & $\begin{array}{l}\text { a service/product that was totally new to the market } \\
\text { (customer) }\end{array}$ & 1 & 2 & 3 & 4 & 5 & 6 & 7 \\
\hline 5 & $\begin{array}{l}\text { a service/product that offered new features vs. } \\
\text { competitive products }\end{array}$ & 1 & 2 & 3 & 4 & 5 & 6 & 7 \\
\hline 6 & $\begin{array}{l}\text { a service/product that required change in the customer's } \\
\text { buying behavior. }\end{array}$ & 1 & 2 & 3 & 4 & 5 & 6 & 7 \\
\hline
\end{tabular}

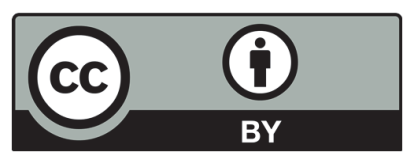

(C) 2021 by the authors; licensee Growing Science, Canada. This is an open access article distributed under the terms and conditions of the Creative Commons Attribution (CC-BY) license (http://creativecommons.org/licenses/by/4.0/). 